\title{
SENSIBLE PROJECT: ÉVORA DEMONSTRATOR ENABLING ENERGY STORAGE AND ENERGY MANAGEMENT CREATING VALUE FOR GRID AND CUSTOMERS
}

\author{
Gisela Mendes \\ EDP - NEW R\&D - Portugal \\ Gisela.mendes@edp.pt \\ Clara GOUVEIA \\ INESC TEC - Portugal \\ Clara.s.gouveia@inesctec.pt \\ Filipe GUERRA \\ EDP - NEW R\&D - Portugal \\ Filipe.guerra@edp.pt
}

\author{
António FERREIRA \\ EDP Labelec - Portugal \\ antonio.claroferreira@edp.pt
Catherine MURPHY-O'CONNOR
INDRA - Spain
cmurphy@indra.es

Luis ROCHA

Luís ROCHA

EDP Labelec - Portugal

luismiguel.rocha@edp.pt

\author{
Ricardo BESSA \\ INESC TEC - Portugal \\ ricardo.j.bessa@inesctec.pt \\ Susete ALBUQUERQUE \\ EDP Distribuição - Portugal \\ susete.albuquerque@edp.pt
}

\begin{abstract}
This paper aims to discuss both the ICT and grid architectures of the Évora Demonstrator under the project SENSIBLE. The demonstrator is focused on testing grid management functions under normal and emergency operation in a rural low voltage grid, taking advantage of electrochemical, electromechanical and thermal storage technologies as well as renewable energy sources (photovoltaics) that will be deployed at both distribution grid and at clients' electrical installation. In addition, the community engagement strategy is presented since it is crucial for the full implementation of the project.
\end{abstract}

\section{INTRODUCTION}

The 2030 EU Framework for climate and energy has defined ambitious targets aiming at helping EU countries to achieve more competitive, secure and sustainable energy systems and promote a low carbon economy. These targets set a $40 \%$ cut in greenhouse gas emissions compared to 1990 levels, at least $27 \%$ share of renewable energy consumption and at least $27 \%$ energy savings compared with the business-as-usual scenario [1]. The increasing amount of renewable energy resources on the production mix has been the regular strategy to achieve a sustainable growth. As a result, balancing the supply with the customers' demand in real time has become even more challenging due to the introduction of more uncertainty and unpredictability of the generation. Therefore, the current grid infrastructure is required to undergo significant adjustments to handle the future challenges, namely higher peak demand, greater control over energy costs, losses reduction and lower O\&M cost. New solutions are being analysed such as demand side management (DSM) and introduction of storage capacity, among others, leading to the implementation of ICT and management tools and ultimately to the concept of smart grids.

SENSIBLE - Storage ENabled SustaInable energy for BuiLdings and communitiEs - was conceived under this context. It is a Horizon 2020 funded innovation action project aiming at integrating small-scale electro-chemical, electro-mechanical and thermal storage technologies, together with Distributed Renewable Energy Sources
(DRES), into the distribution grid, homes and buildings. The benefits of storage integration will be demonstrated in three demonstrators: Évora (Portugal), Nottingham (UK) and Nuremberg (Germany). The Portuguese demonstrator will be implemented in a rural grid, which is considered weak and potentially unreliable. The focus will be to demonstrate storage-enabled power flow, power quality control and grid resilience/robustness in (predominantly low-voltage) power distribution networks. The Nottingham demonstrator will be implemented in a social neighbourhood with a high level of environmental commitment. It will focus on storage-enabled energy management and energy market participation of buildings (homes) and communities. The local grid is considered strong, thereby with no or few restrictions from the grid. The Nuremberg demonstrator will be deployed inside THN (Nuremberg University) and Siemens A.G. laboratories. It will focus on multi-modal energy storage in larger buildings, involving thermal storage, combined heat and power, and different energy vectors (electricity, gas). The ultimate goal of SENSIBLE project is to create value for distribution grid operation, market players and endusers. Moreover, flexibility-based business models will be proposed based on connecting the local storage capacity with the energy markets, at the individual and aggregated level. SENSIBLE will also conduct life cycle analyses and assess the socio-economic impact of small-scale storage integrated in buildings and distribution grids. The project started in January 2015 and ends in June 2018. It is led by SIEMENS A.G., whereas EDP Labelec leads the demonstration work package. The Universtity of Nottingham, Adevice, Armines, Empower, GPTech, Indra, Inesc, Mozes, University of Sevilla, Technische Hochschule Nurnberg, Siemens S.A. and K\&S take also part in the consortium, along with EDP Distribuição as third party of EDP Labelec.

\section{ÉVORA DEMONSTRATOR}

This paper is related to the Portuguese demonstrator, located in Valverde, a small village in the countryside of Évora. The test bed is located at the end of a MV feeder with no redundancy and it is composed by 3 secondary substations (SS), of which two are DSO owned and the third one is client owned. Both DSO owned SSs feed a rural LV grid and each one has $250 \mathrm{kVA}$ rated power, comprising in total $238 \mathrm{LV}$ clients. The client owned SS 
belongs to a campus of University of Évora and has a peak consumption power of $500 \mathrm{kVA}$. The demonstrator is mainly focused on testing solutions of energy management and energy storage systems for distribution grid management, both under normal and emergency operation. Equipment and tools will be primarily submitted to a laboratorial validation shared between INESC Porto and EDP Labelec. The objectives of the demonstration work are materialized into 5 use cases, of which 4 are mainly related with grid management and the remaining use case is focused on client flexibility and demand management, aiming at optimising clients' energy demand. The solutions developed for grid management try to solve future challenges such as degradation of voltage profiles (overvoltage and undervoltage), reduction of technical losses and increased renewables penetration.

Use case 1 - Optimizing the MV distribution network operation using available storage resources

The main goal of this use case is to manage the MV distributed storage system with a rated power of $472 \mathrm{kVA}$ and a capacity of $360 \mathrm{kWh}$ in order to solve technical problems at the MV network level such as degradation of voltage profiles and losses. The management and operation of the storage device have two objectives: (a) reserve capacity to support continuity of service of an installation (or building) following unplanned interruptions and (b) provision of grid support services by exploiting the remaining capacity of the energy storage system.

Use case 2 - Optimizing the operation of storage devices in the $L V$ network

The main goal of this use case is to manage local distributed storage devices in order to solve technical problems in the LV grid, namely related to steady state voltage profile, and minimize technical losses. The storage devices are to be coordinated with renewable generation at the LV level as well as with demand side management schemes, considering residential storage and controllable loads.

Use case 3 - Islanding operation of $L V$ networks

The main goal of this use case is to enable the operation of LV networks in islanding mode, ensuring a secure transition to islanding operation and the system stability as well as the transition to the connected operation, by providing adequate frequency and voltage regulation mechanisms.

\section{Use case 4 - Microgrid emergency balance tool}

The main goal of this use case is to manage a microgrid (MG) properly, in order to (a) minimize energy not supplied and time of service interruption, (b) ensure that the MG has sufficient capacity to ensure frequency regulation following islanding and c) maintain frequency excursions within admissible limits.

Use case 5 - Flexibility and DSM (Demand Side

\section{Management) in the market participation}

The goal of this use case is to take advantage of LV customers' flexibility to enhance their energy cost through market participation (wholesale and retail) and optimize the operation of distribution grid to allow grid investment deferral.

\section{POWER GRID ARCHITECTURE}

The power grid of Évora Demonstrator embraces two distribution secondary substations (MV/LV substations) and a client owned secondary substation. At the MV level, there is also an Energy Storage System as part of other EDP Distribuição project [3], although the use case related to the optimization of the MV distribution network operation will also address this system.

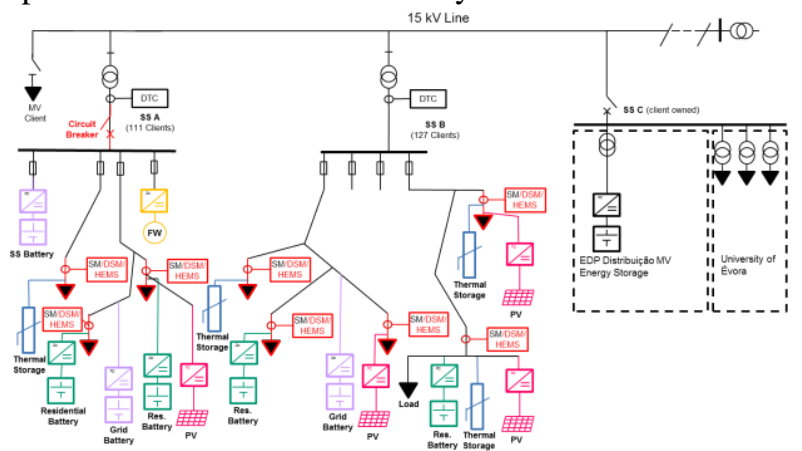

Figure 1 - Power Grid architecture of the Évora demonstrator

Figure 1 represents the power grid architecture for the Évora demonstrator, where the elements depicted in colour will be deployed under the scope of SENSIBLE project, namely:

- A circuit breaker between the transformer's LV side and the LV secondary substation switchgear. It will be installed in secondary substation A (SS A, at the left hand side of Figure 1) to enable the creation of a microgrid;

- Distribution Transformer controller (DTC) concentrates data collected by all smart meters and send it to the upstream central systems. It is responsible for sending to smart meters DSM signals. It is also responsible for managing the storage units installed in the grid.

- Electrochemical storage units (one battery with $100 \mathrm{kVA}$ ) and an electromechanical storage unit (flywheel with $125 \mathrm{kVA}$ of rated power) will be integrated and connected at the SS A LV busbar, aiming to test different functionalities and capabilities of energy storage in grid operation. Electrochemical storage units (4 units with $30 \mathrm{kVA}$ and 2 prototype units with $10 \mathrm{kVA}$ ) will also be installed in other points of the LV grid, along the feeders, enabling different applications like technical losses' reduction, voltage control and renewable energy sources 
integration.

- Smart meters that enable DSM functionalities and provide valuable data for the operation of $\mathrm{LV}$ systems by characterizing the energy consumption and voltage in each node of the network. Smart meters also provide important information to clients, through a Home Area Network (HAN) port where a HEMS can be connected.

At residential level, behind the meter, a set of devices will be installed in an extensive number of clients:

- Residential electrochemical storage units and thermal storage units (water heaters);

- Photovoltaic (PV) Systems as a form of microgeneration;

- Home Energy Management Systems (HEMS), Controllable Smart Plugs and other smart home devices aimed at integrating, controlling and managing customer's applications;

\section{ICT ARCHITECTURE}

Along with equipment to be installed in the existing grid, an ICT infrastructure has to be deployed in Évora to support the implementation of the Use Cases. Figure 2 represents the block diagram of the Évora demonstrator' ICT architecture, which encompasses 5 main blocks.

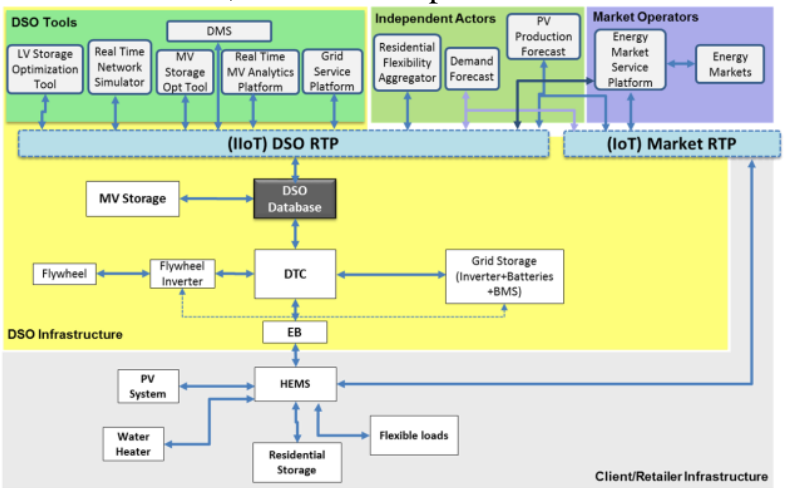

Figure 2 - Block diagram of the Évora demonstrator ICT architecture

The information between blocks flows through RTP (Real Time integration Platform) which is a middleware communication infrastructure for real-time data acquisition and processing, with the ability to handle large volumes of information at low latency. Besides, this platform is able to minimize the number of queries to the infrastructure and make available common information to different systems/ functionalities. This platform is divided into two due to regulatory issues: DSO RTP and Market RTP.

\section{Client/retailer infrastructure}

The client/ retailer infrastructure represents the participation of residential/ services clients. The most important element is the HEMS (Home Energy
Management System) which is responsible for managing the local resources such as PV system, water heater, residential storage and some controllable loads.

\section{DSO infrastructure}

The DSO infrastructure is responsible for managing and control the distribution network as well as concentrating and processing the data collected from smart meters. The DSO infrastructure can be divided in the following components:

- $\quad$ Advanced Metering Infrastructure (AMI), which is composed by DTC and EB (EDP Energy Box, i.e. smart meter).

- The DSO Database represents the existing grid distribution management system, which encompasses the AMI application, the grid control and operation modules and the data collection and provision components. This component collects all the data communicated via DTC and acts as a middleware between the downstream smart grid (and all the grid connected devices) and the upstream RTP.

\section{DSO Tools}

DSO tools incorporate the main algorithms and systems required for the operation of $\mathrm{MV}$ and $\mathrm{LV}$ networks considering the integration of storage, micro-generation and flexible loads. Given the different nature of MV and LV networks, two optimization tools are under development to enable Use Cases 1 and 2. Considering the storage capacity installed at the LV level, the network can also operate in islanded mode (Use Case 3). In order to improve the security of operation, the MG Emergency tool will monitor the islanded system and manage storage capacity in order to maintain the security of operation and avoid the network collapse (4).

\section{Independent actors}

This block comprises three tools: PV Production Forecast, Electric Demand Forecast and Residential Flexibly Aggregator. The inputs of the forecast tools are real time measurements of electric demand, historical data and weather forecast. The outputs are the electrical demand and PV generation for each client. This information will be used by DSO tools and by the market platform. In addition, the Residential Flexibility Aggregator is responsible to both aggregate clients' flexibility and allocate the necessary flexibility for each client.

\section{Market Platform}

The Market Platform includes both the EMSP (Energy Market Service Platform) and the Energy Markets components that will emulate an energy market for enabling the Use Case 5.

\section{COMMUNITY ENGAGEMENT}

The success of SENSIBLE project depends on the full 
engagement of all stakeholders so EDP identified all the stakeholders to be involved in the Évora demonstrator (including critical stakeholders identification), and then designed specific engagement initiatives for each project phase, in order to manage community expectations. Local authorities, regulatory entities and the community of Valverde will be will be directly reached within the project, though the inhabitants of Valverde are key actors for the success of the Évora demonstrator, since some of equipment will be installed at their homes/ businesses. Thus, the majority of the engagement actions are tailored for this group of stakeholders in order to assure a transparent and effective communication between the project team members and the inhabitants as well as to make people feel confident about new technologies and about the project as a whole. Taking into account that Valverde community's engagement is quite challenging since it is a rural community, a top down approach was followed. Firstly EDP met with the local mayor to gather his support on the project and to discuss the best strategies for the engagement of the local community. A first dissemination session was arranged to present the main ideas of SENSIBLE project to the community and to gather their main expectations and concerns. A second session was held three months later to provide a more detailed description of the equipment to be installed at buildings/ residential level and to explain briefly the participants' selection process. In addition, a questionnaire was made to access how many households or small business/services were willing to participate in the project. The next most important actions foreseen for the Évora demonstrator are described in Table 1.

\section{Table 1 - Future activities involving the community}

\begin{tabular}{|l|l|}
\hline \multicolumn{2}{|l|}{ Date } \\
$\begin{array}{l}1^{\text {st }} \text { quarter } \\
\text { of 2016 }\end{array}$ & $\begin{array}{l}\text { Individual sessions with the inhabitants } \\
\text { who will have equipment at their } \\
\text { homes; } \\
\text { Signing the agreement between each } \\
\text { client and EDP, where the rights and } \\
\text { duties of both parts are detailed. }\end{array}$ \\
\hline $\begin{array}{l}2^{\text {nd }} \\
\text { semester } \\
\text { of 2016 }\end{array}$ & $\begin{array}{l}\text { Workshop about the residential } \\
\text { equipment and its installation (PV } \\
\text { systems, storage devices and HEMS). }\end{array}$ \\
\hline Year 2017 & Tests and validation \\
\hline June, 2017 & Session about the first results \\
\hline May, 2018 & Final event to disseminate the findings \\
\hline Biannual & Newsletters and newspapers articles \\
\hline
\end{tabular}

The community involvement is conducted under strict rules, according to ethical procedures report, that can be grouped in four critical aspects: (1) Informed clients: Participants should be entirely informed about the project; (2) No discrimination: It is against the EDP procedures to discriminate against anyone namely because of his/her energy retailer; (3) Data confidentiality: EDP must ensure that all data collected throughout the project, either consumption data, billing data or other sensitive information, is kept confidential and codified, even after the project ends; (4) Local Stakeholder Engagement Methodology: EDP has its own methodology to deal with local stakeholders, called COMPRO [4], which is being applied to the Évora demonstrator.

\section{CONCLUSIONS AND FUTURE WORK}

SENSIBLE is a challenging project aiming at demonstrate and validate the benefits of storage both at distribution grid and clients level. Several tools to be integrated on the ICT infrastructure are under development, whose main goal is to optimise grid operation taking advantage of storage devices. The benefits of storage at clients' level will be addressed by using their flexibility for minimizing their energy costs along with contributing for grid management. The community engagement is key, since equipment will be installed at clients' side and their collaboration is a requisite to run the Use Cases.

The demonstrator of Évora constitutes one more step towards smart grids of the future. Further work embraces laboratorial validation, deployment of the infrastructure, demonstration tests by running the uses cases and lastly a proof of concepts.

Furthermore, Évora demonstrator's ambitions encompass the development of business models as well as providing recommendation for a new regulatory framework to foster the introduction of new energy storage concepts along with distributed renewable energy resources.

\section{ACKNOWLEDGEMENTS}

This work is being carried out as a part of the SENSIBLE project (Storage ENabled SustaInable energy for BuiLdings and communitiEs - www.h2020-projectsensible.eu) that has received funding from the European Union's Horizon 2020 research and innovation programme under grant agreement No 645963.

\section{REFERENCES}

\section{[1] Webpage European Commission/Energy} http://ec.europa.eu/energy/2030_en.htm [2] Webpage project SENSIBLE http://www. h2020-project-sensible.eu/sensible/index.aspx [3] R. André et al, "EDP Distribuição's INOVGRID first electrical energy storage project", Proceedings of the 23rd International Conference on Electricity Distribution (CIRED), Lyon [4] I. C. Silva, et al, "Communication project of primary substations and surrounding network", Proceedings of the 23rd International Conference on Electricity Distribution (CIRED), Lyon 